\title{
Interpretación de El Habitante y su Esperanza, de Pablo Neruda
}

\author{
"...la naturaleza allí me daba una especie de \\ embriaguez. .." PABLO NERUDA, "Infancia y poe- \\ sia", prólogo a sus Obras completas, Buenos Aires; \\ Ed. Losada, 1956.
}

Varias son las razones que me han movido para centrar mi atención en esta breve obra de Pablo Neruda, y enumerarlas antes de intentar su análisis me parece necesario.

La obra de Pablo Neruda, que ha completado ya medio siglo, resulta hasta ahora, y prescindiendo de todo afán valorativo, descomunal. No existe en lengua hispana, ni acaso ha existido nunca, poeta de fecundidad semejante. Se inició en 1919 con Crespusculario y desde entonces su producción aumenta cada año con dos o tres nuevos títulos. En cuanto a su calidad, materia eminentemente subjetiva, no quiero anotar sino como señal significativa el abundantísimo número de traducciones a casi todas las lenguas vivas del planeta y la consideración reiterada de su nombre, durante estos últimos diez años, por el jurado encargado de discernir el Premio Nobel de Literatura, máximo galardón para la obra de un contemporáneo.

En esta labor prolongada es fácil advertir la evidente preferencia que el escritor ha concedido al género lírico, al que ha consagrado cerca de cuarenta volúmenes. Sólo excepcionalmente ha publicado libros en prosa: Anillos, El babitante y su esperanza, Viajes y La casa en la arena. Una sola pieza teatral registra su bibliografía: Fulgor y muerte de Joaquin Muriela. De sus libros en prosa el único que aspira a ser considerado novela es El babitante y su esperanza. Para esta consideración influye el hecho de que su autor ha mantenido en las sucesivas ediciones la palabra "novela", entre paréntesis, bajo su título. No obstante ese detalle habría 
motivos válidos para, al menos, cuestionar tal calificativo. El primero sería meramente físico: El cuerpo de la novela, que abarca sólo doce páginas en la edición de sus obras completas ${ }^{1}$ y que en la primera edición, con prodigalidad de márgenes y tipografía desmesurada, apenas si superaba a lo que podría llamarse un folleto. Como se sabe, en Francia, cuando un cuento excede las veinte páginas se hace acreedor al apelativo de "nouvelle", género intermedio entre el cuento y la novela. Utilizando ese patrón, esta obra ni siquiera alcanzaría a merecer la calificación de "nouvelle".

Pero más importante es la consideración interna de la obra. ¿Es el mundo que ella despliega un mundo novelesco? ¿Y es la forma, el modo como ese mundo se nos entrega, el habitual del género "novela"?

No es el propósito de este trabajo llegar a responder inequívocamente a esta pregunta ni catalogar de manera definitiva esta obra literaria. Es posible que en el desarrollo de las siguientes argumentaciones aparezcan elementos que puedan contribuir a una determinación más ceñida de su género, pero el propósito inicial es, simplemente, ofrecer una interpretación ajena a la consideración del género del material literario encerrado bajo ese título de $E l$ babitante y su esperanza.

Con ser Neruda uno de los escritores vivos que más estudios ha merecido de filólogos y críticos, esta obrita aparece extrañamente huérfana de apreciaciones o referencias críticas. El trabajo de Amado Alonso ${ }^{2}$ se concentra en el análisis de los poemas de Residencia en la tierra y sólo de paso alude a la obra anterior de Neruda; ni una línea de su libro menciona esta "novela". El estudio que sigue en importancia al de Alonso, y le sobrepasa considerablemente en extensión, es El viajero inmóvil, de Emir Rodríguez Monegal,3 y que, no obstante su volumen, sólo concede cinco líneas desdeñosas a El babitante $y$ su esperanza, libro al que juzga publicado con algún apresuramiento. Casi todos los críticos se han contentado con referirse a la novelita como un relato de cuatreros australes o de aventuras eróticas en un ambiente más - menos apócrifo. ${ }^{4}$ En cuanto a su forma, se dividen los opinantes entre los que la aceptan como un "relato" y los que la consideran o un "cuento largo", o una serie de poemas en prosa, o una sucesión de "close-ups" estupendamente vestidos. ${ }^{5}$

1 Pablo Neruda, Obras Completas, Buenos Aires, Ed. Losada, 1a. Ed. 1956, pp. 93-109.

a Amado Alonso, Poesia y estilo de Pablo Neruda: interpretación de una poesía bermética. Buenos Aires, Ed. Sudamericana.

3 Emir Rodríguez Monegal, El viajero inmóvil. Buenos Aires, Ed. Losada, 1966.

4 Ibid, p. 54.

5 Alfredo Cardona Peña, Pablo Neruda y otros ensayos. México, 1955, p. 24. 
La excepción quizá, la of rece Alone, el crítico chileno que estimuló a Neruda desde sus comíenzos y quien no obstante sus preferencias por las virtudes clásicas de claridad, sencillez, naturalidad y orden, reconoce que en este pequeño libro

...mediante toques esenciales, adivinatorios, el poeta sugiere los hechos y cada golpe da tan al justo que parece como si no faltara nada. (...) Con la mayor sencillez, sin perder su aire ausente, dice las cosas externas y las interiores, salta de unas a otras sin ligarlas por nexo visible y de ese modo habla, dibuja, pinta, canta, encanta."

La breve cita me parece of recer respuestas provisorias para algunos de los interrogantes que nos hemos formulado. Dice el crítico que los golpes son tan justos que "parece que no faltara nada". Veo en ella una apreciación más justa respecto a la consideración, todavía externa, de la obra. Si un relato, por breve que sea, deja la sensación de que ha logrado desplejar toda su materia, podrá, acaso legitimamente, ser considerado como novela aunque no sobrepase los límites físicos del cuento. $\mathrm{Y}$ es que el modo cómo un poeta trabaja su material es radicalmente diverso al del novelista. Aquél es económico y su avance no debe medirse por frases. Un adjetivo, tantas veces, $\mathrm{d}_{a}$ con su justeza -o con su des. ajuste- noticias que tomarian páginas a un narrador.

Otro aspecto destacable de la cita de Alone es la referencia que hace a la doble realidad del libro, externa e interna, y al hecho de que el autor salte de una a otra sin ligarlas por nexo visible.

En otra parte de su reseña, declara:

Es un relato. Hay una casa, un hombre, una mujer, hay otro hombre, un amor, un robo, hasta hay una prisión y un asesinato seguido de fuga. Todo ello en silencio, deslizándose, bajo un agua nítida, en medio de los árboles, junto al mar, por los campos nocturnos de la Frontera.

Me parece que sí, que ésa sería una buena síntesis de la acción me. dular. Con la salvedad de que sería posible intentar otras diez o veinte completamente diferentes e igualmente válidas.

Sorprende el menosprecio de la crítica hacia este libro que, sin argumentaciones de peso, lo ha pasado por alto, con la sola excepción, anota.

- Hernán Dídz Arrieta (Alone), Los cuatro grandes de la literatura chilena. Santiago, Zig-Zag, 1963, p. 186. 
da, de Alone. Debió alertarlos, a mi juicio, si no ya su calidad misma, la ubicación relativa que ocupa en la cronología de la obra nerudiana.

Se consideran como obra máxima de este autor sus tres tomos de Residencia en la tierra. En especial los dos primeros que contienen poemas escritos entre 1925 y 1935. Ahora bien, los libros que Neruda es. cribió en el periodo inmediatamente anterior a sus Residencias fueron Tentativa del Hombre infinito y El babitante y su esperanza, ambos publicados en 1926. Del primero de ellos su autor ha declarado más de una vez que es el libro menos leído y menos estudiado de su obra y, sin embargo, "es uno de los libros más importantes de mi poesía."7 Tampoco existe ningún buen estudio de ese largo poema aunque la crítica ha mantenido una actitud más respetuosa hacia él, en parte, seguramente, debido a la declaración antedicha.

En general se ha reconocido que en esa producción anterior a las Residencias, cuando el autor comenzaba a transitar los caminos surrealistas, está en ciernes el mundo "residenciario". "La Testativa del bombre infinito es el pórtico oscuro, en clave, de Residencia en la Tierra", dice Rodríguez Monegal, coincidiendo con varios críticos anteriores. ${ }^{8}$

Pero es, como digo, sorprendente, que nadie haya considerado el otro libro que Neruda publica en ese mismo año. ¿Por qué sólo uno de ellos ha de ser peldaño importante en esa escala ascendente que corona con Residencia en la tierra la principal etapa de la obra nerudiana? Con mayor razón, si se tiene en consideración la extraordinaria unidad que, no obstante las variaciones de metro y estilo, favorece las diversas etapas creadoras del poeta chileno.

Nuestro sencillo propósito es el de penetrar, amparados de intuición y método, a una obra literaria. Querríamos lograr la mayor claridad, poder interpretar $y$, como consecuencia, poder evaluar. Sin embargo, tal como lo hace Dámaso Alonso al aproximarse a la poesía de Garcilaso reconociendo los límites de la estilística frente a la materia lírica, debo advertir que en este relato dé Neruda, por más que extrememos nuestro afán viviseccionador, no lograremos entender por completo. Es que quizá tenga razón nuevamente Alone cuando se pregunta y se responde a sí mismo:

¿Por qué no podríamos tener otro órgano para leer estas cosas? Hallar una circonvolución virgen y confiarle la literatura nueva. Que el resto de la maquinaria siga funcionando como siempre.

7 A. Cardona Peña, Op. cit., p. 20.

8 E. Rodríguez Monegal, Op. cit., p. 54. 
Y que cada vez que abramos un libro semejante sea como si aspiráramos un opio sutil, como si empezáramos a dormirnos o no hubiéramos despertado todavía. Abrirle otra puerta al universo, entrarse por campos y regiones inexplorados, navegar más allá de los mares, volar más lejos que el aire.. ${ }^{\circ}$

He anotado el lugar privilegiado que esta obra ocupa en la cronología nerudiana. Escrita en un período de máxima fecundidad y de fervor dionisíaco, resulta bastante novedosa dentro de la tradición hispanoamericana y absolutamente contemporánea del movimiento surrealista que dirigían por ese entonces, en Europa, Breton y Aragon. El primer manifiesto surrealista había aparecido en Francia en 1924, La paysan de París, de Aragon, se publicó en 1925, y Nadja, de Breton, recién en 1928.

No obstante su contemporaneidad con muchos de los recursos formales del surrealismo, existe en la obra de Neruda algo fundamental que la distancia de él y es el tono interior del personaje a cuyo cargo corre la marración y en quien adivinamos la subjetividad propia del poeta, tono marcadamente romántico del que Neruda no ha podido -0 más probablemente no ha querido-- liberatse hasta hoy. Esa contradicción entre la forma vanguardista y el contenido predominantemente tomántico viene a oponer una dificultad más en el momento en que se quiere ubicar esta obra dentro de la tradición histórico-literaria.

No es ésta una obra que entregue todo su contenido luego de un ataque unilateral. Me parece aconsejable intentar la penetración por ambas vías: a partir de la forma interna considerándola una obra de ficción susceptible de ser desmenuzada en su triple contexto de acción, personajes y pensamiento; y luego, a partir de la forma externa, considerándola un largo poema que requiere, como cualquier otro, un estudio progresivo de sus diversas estrofas, atendiendo de modo preferente a las formas y recursos expresivos, a la dicción del hablante.

Hay una acción medular superficial que nos arriesgariamos a resumir así: es la historia del asesinato de una mujer por su marido, en razón de amores que ella mantenia con un compañero suyo de fechorías, a lo que sigue un intento posterior de venganza no materializada.

$\mathrm{O}$, mejor dicho: es el propósito de un apasionado cuatrero-lírico de tomar venganza en contra del marido de su amante, a la vez compañero suyo de correrías, quien la ha asesinado, huyendo posteriormente.

- H. Díaz Arrieta, Op. cit., p. 185. 
Pero, como ya he dicho, no es posible, ni aun limitándonos a la acción externa, resumirla de un modo adecuado porque en este libro las cosas suceden y no suceden al mismo tiempo. $\mathrm{L}_{a}$ acción no está presidida por la lógica ni las cosas o personajes son definitivamente lo que aparentan ser. Ni se puede calificar, sin más, de bandolero al narrador ni de vengativos a sus propósitos. Ni puede siquiera afirmarse que la acción exterior principal sean los amores suyos con Irene, el crimen de Florencio y su propósito de venganza. Podría argumentarse válidamente que la acción medular es, en cambio, la sucesión de acontecimientos rutinarios que van afectando de modo pasajero, cíclicamente, a los hombres y la necesidad que éstos tienen de encontrat alguna razón vital, alguna esperanza que justifique su pasión.

La acción está dispuesta en quince capítulos brevísimos, la mayor parte de 4 o 5 párrafos, sin ilación entre ellos. Por lo general, cada capítulo se contenta con una escena que se presenta apoyada por pocas pero muy vigorosas imágenes visuales y una variable cantidad de comentarios que el narrador entrega sobre ella o sobre escenas anteriores o aun sobre episodios desconocidos del lector. Los comentarios adoptan la forma del monólogo y más tienen del tono de exaltación lírica, el elogio o la queja enfatizadores, que de complementos objetivos de la acción. No llega a lograr el narrador, pues, y quizái ni lo intenta ni lo desea, la credibilidad absoluta del lector. Contribuyen para ello varios elementos: a) la confusión inherente a la materia relatada. El mismo declara que no com. prende del todo lo que ocurre, lo que le ha ocurrido; b) las frecuentes contradicciones de sus afirmaciones, y c) la tonalidad ambigua de su dicción, o, mirado desde el punto de vista del estilo, la sintaxis anómala.

No se crea, sin cmbargo, que el hablante no pretende establecer nin. gún vínculo con su auditor. Es posible que éste le niegue credibilidad en el plano en que habitualmente cualquier narrador en primera persona lo consigue, en ese plano superficial de las ideas que se declaran, de los acontecimientos que se relatan. La comprensión por la que el narrador se afana es una más cabal, más profunda, la que se logra establecer en un plano más hondo y firme en el cual las contradicciones o los errores dejan de tener importancia. Y asi ese personaje impuro, que considerado en su apariencia y juzgado por los cánones sociales y legales en uso debe ser confinado en los casilleros marginales, resulta dotado, en cambio, de valores más refinados y estricto observante de una "moralidad" más personal. Es en esa zona inédita, a la que no llegan a regir leyes ni convenciones, donde el narrador espera ser juzgado por el lector y 
obtener de él su aprobación o condena. Para ello nos relata su historia con una veracidad superior, como si desdeñara olímpicamente nuestro juicio. Como un masoquista acumula circunstancias adversas al relatar, sin piedad, sus propios actos y propinándose seguidamente adjetivos des. valorizadores.

Pero es necesario afinar la atención. La acción que se describe está relatada en forma cronológica. No todos los capítulos avanzan sensiblemente en el tiempo, pues algunos se limitan a glosar los hechos, pero no existen propiamente retrocesos en la presentación de la acción.

Los dos primeros capítulos nos entregan, con breves pinceladas, el escenario donde se desarrollará la historia. Es un lugar imaginario en la costa, frente a unos cerros. Es un pueblo pequeñísimo, apenas un conjunto de casas. Casi no hay civilización. Aparecen fugazmente, y seguirán transitando el relato, comerciantes, ladrones de animales (cuatreros), indios, trabajadores y viajeros. El hablante se describe en estos tramos como un ser indolente, profundamente contemplativo de la naturaleza, sin una razón demasiado poderosa por la cual vivir. Describe, sin gran entusiasmo, a una mujer, Irene, y da algunos rasgos para señalar el tipo de rela. ción que mantiene con ella.

El capítulo tercero describe un robo de animales que ha realizado acompañado de otro personaje: Florencio Rivas.

Los capítulos cuarto y quinto ocurren en la prisión de Cantalao, donde ha ido a caer nuestro héroe a consecuencia de su robo. Se lamenta mo. deradamente de la pérdida de su libertad y escribe una carta a un amigo pidiéndole noticias de Irene.

En el capítulo sexto el narrador ya ha recuperado su libertad y ha ido en busca de la mujer amada. Se describe el juego amoroso.

En el capítulo séptimo recibe, de noche, la visita intempestiva de su amigo Florencio Rivas, quien le urge a levantarse y a acompañarle en un viaje. El narrador nos confidencia su certeza de que Florencio ha dado muerte a su mujer, Irene.

En el capítulo octavo las sospechas se confirman. Encuentra a Irene muerta en una casa abandonada hasta donde lo ha llevado Florencio en el capítulo anterior.

El capítulo noveno es una pura descripción lírica del otoño en el que no ocurre ninguna acción visible.

En el décimo, relata jirones de una huida que el nartador intenta para escapar del agobio que le provoca su estado. En su camino va encontrando obsesivamente a Irene detrás de cada una de las mujeres que trata. 
En el undécimo hay una prolongada descripción de un fragmento de vida del narrador con Lucía, mujer con la que tiene un amotío intrascendente. La vida aparece en toda su rutina e insignificancia provinciana. Sin embargo, el poderoso aliento lírico del narrador es capaz de sobreponerse y forjar una nueva esperanza, superada aparentemente su desazón por la pérdida de Irene.

En el décimosegundo se describe la inmovilidad del tiempo, que transcurre sin que nada suceda. Sin embargo, la actitud del hablante es descontentadiza, acongojada.

El décimotercero muestra al natrador de vuelta a una actividad relativamente útil. Es dependiente de un almacẻn y las infimas alternativas de tal vida se señalan con breves trazos. Irrumpe Irene con la apariencia de un "flash-back", aunque se descubre luego que no es ella, es sólo la persistencia de su recuerdo que obsede a su ex-amante. Este capítulo cierra el ciclo de la huida que se había iniciado en el capítulo décimo.

De pronto todo se aclara en el capítulo catorce. El propósito del hablante es el de vengarse. Se nos hace partícipes de los planes para llevar a cabo esta acción. Así pretende el protagonista liberarse del agobio que lo aqueja y salvar su vida de la vacuidad en que ha caído, impedida del puro contacto, libre y espontáneo, con la naturaleza.

El capítulo 15 y final concluye, de manera alucinante, el propósito vengativo del narrador. En la realidad o en sueños (me inclino fuertemente a esta última posibilidad) él enfrenta finalmente al hombre a quien debe matar, peto le es imposible consumar su acción. Termina el relato con el narrador contemplando un amanecer frente al mar y la sensación de que todo el episodio ha concluido y comienza un nuevo ciclo.

En cuanto a los personajes que transitan este relato, es necesario advertir que, a excepción del narrador, cuya importancia es para nosotros capital, puesto que es su vigoroso mundo subjetivo el que se nos entrega, el resto es puro esquematismo. Los personajes están descritos con una gran economía verbal. A veces, bastan dos o tres rasgos para caracterizarlos. Contrasta esta vertiginosidad con la morosa descripción del paisaje. Frente a la magnificencia opulenta de la naturaleza que se despliega ante nuestros ojos no hay ningún elemento que oponerle. La acción resulta banal; los personajes, ínfimos. Sólo admitiría comparación con otro paisaje interior: la dimensión lírica del hablante, única mag. nitud equivalente. 
Al narrador le conocemos más que por las escasas informaciones objetivas que nos ofrece de su personalidad, hábitos, oficios y pasiones, por su dicción. Cualquiera que sea su calidad moral, cualquiera que sea su ocupación ciudadana, él se nos aparece como un poeta. Un contemplador persistente de las bellezas naturales, particularmente sensible a la grandeza del océano, de la noche, al cambio de las estaciones.

Al comenzar la acción es un hombre tranquilo, según dice, porque no tiene temor de la muerte ni pasiones. Se declara indolente, esto es, negligente, perezoso. $Y$ así se explica que se detenga sin prisa en la contemplación del mar, de la atmósfera, de la gente y de los vehículos que pasan. "Me gusta ver" es el estribillo de ese primer capítulo y muestra bien una característica importante del narrador. Sus ocupaciones son varias y no siempre legítimas. Las desempeña como distante, como si fuesen apenas simbólicas. Sin poner en ellas su vida, sin entregarse, está como buscando en ellas, o fuera de ellas, o a pesar de ellas, una esperanza que justifique su vida. Esta se desenvuelve al margen de su oficio. Vive para su ocio. No busca lucro en sus acciones, sólo las alegrías de su destreza y ésta puede consistir en robar ganado o galopar violentamente a orillas del mar. Ninguna preocupación ética, pues. Sólo una inflexible norma interior, semejante a aquella que postulaba el juvenil héroe de Hesse, Demián: "tendía a hacer sólo aquéllo que brotaba espontáneamente de mí." En esta relación tan estrecha con la naturaleza el protagonista ha desarrollado una confianza en sí mismo casi ilimitada dentro del pequeño territorio en el que se ejerce. Dentro de sus límites cabe la capacidad de anticiparse a los acontecimientos: don profético connatural a la condición del poeta o producto de su exacerbada capacidad observadora que le permite, a partir de detalles casi invisibles, deducir consecuencias exactas. Así, pues, en la cárcel ya "ve" a Irene pasando malos momentos, y luego, al llegar Florencio a buscarlo en mitad de la noche, "sabe" que él ha dado muerte a su mujer.

Luego de ese hecho que lo conmueve hondamente pero que no logta moverlo a ninguna acción, aflora la única postura metafísica de todo el relato. Enredado, como ha estado hasta ahora, en lo inmediato, no ha tenido ni el estímulo ni la preocupación para preguntarse a fondo sobre nada. $\mathrm{Ha}$ estado contemplando y absorbiendo, y secundariamente, actuando. Ahora, ahí, en esa casa abandonada frente al mar con el cuerpo desnudo y muerto de la mujer amada, cuando él sólo quisiera escuchar su voz, ese sonido próximo e íntimo e intrascendente, tiene en cambio 
su presencia, como un sonido ya muy grande, que le obliga a "poner atención sorda, exasperada, hasta una gran distancia".

En ese momento advierte que quizá su modo de aproximación a la realidad ha sido fragmentario, incompleto, acaso ineficaz. $Y$ luego de esa interrogante surge de inmediato, a modo de autorrespuesta, su afirmación: "Todo es misterioso."

Y perdemos su voz. Sólo le vemos en la acción que despliega, primero reaccionando ritualmente: velándola toda la larga noche y al amanecer nuevamente galopando sobre su caballo en un acto casi rutinario pero ahora con una importante diferencia: el jinete que cabalga no es el mismo que ayer llegó hasta la casa abandonada.

Ese instante es como un gozne en torno al cual gira el relato. El protagonista ha perdido su serenidad elemental, aquélla que le permitía una relación armónica con el medio y que provenía de no temer la muerte ni abrigar pasiones. Esos dos pilates de su personalidad han sido aquí violentados. Ha entrado $l_{a}$ muerte en forma tan rotunda que le ha arrebatado a la mujer amada. Por primera vez, pues, advierte su existencia, su cercanía y su poderío. Y también la pasión, esto es, el desorden afectivo del ánimo. Ese amor fluido, cadencioso, que sentía por Irene, se ha trocado en sentimiento desesperado. 'Igualmente, en otra zona del alma, donde se aloja la amistad, también hay revuelo... En los seres que viven sometidos por una naturaleza hostil, suele la amistad adquirir gran intensidad, no obstante la parquedad con que se manifiesta. Hasta ese linde ha llegado la conmoción y en adelante el protagonista huirá o perseguirái de manera diferente a Florencio Rivas. $\mathrm{La}$ actitud, generalmente levantada, con que hasta aquí ha contemplado el paisaje, y que ha obrado sobre su ánimo un efecto benéfico $y$ afirmativo, se troca sutilmente en este punto y todo el capítulo noveno nos of rece un nuevo modo de mirar en el hablante $y$, en consecuencia, una naturaleza diferente. En ella aún sus partículas menores, como las hojas de los árboles y los pájaros, son movidos por la pasión y todo está impregnado de muerte. Todo marcha hacia el ocaso. Todo está destiñendo, deshaciéndose. Sin embargo, todo tiene también una posibilidad de recobrarse, nada está definitivamente perdido (en contraste, que no necesita expresarse, con la mujer cuya vida se ha tronchado irremediablemente). Así lo expresa el narrador al terminar su prolongado monólogo descriptivo del otoño:

...ay porque todo eso quiere recobrarse hacia su verdadera, ig. norada vida secreta y tira a regresar sin sentirse demasiado muerto. 
Originada en ese acto brutal comienza entonces una nueva vida. Apenas si se nos describe la congoja de quien ha visto sacudida su vida de manera tan radical y que debe entonces tomar algún camino. Ya lo habiamos oído en profético lamento:

El anochecer es igual en todas partes, frente al corazón del hombre que se acongoja, vacila su trapo y se arrolla a las piernas como vela vencida, temerosa. Ay, del que no sabe qué camino tomar, del mar o de la selva...

El mismo tiene también dos alternativas en este momento en que se ve forzado a tomar alguna determinación. Ocurre que alguien en ese entonces, quizá por motivos semejantes, da muerte a otro hombre con una rápida acción. "Ese es el verdadero camino", expresa nuestro héroe, pero ya la contradicción ha entrado en su vida y en vez de imitarle emprende el camino opuesto: "yo escogí la huida", nos confiesa y los próximos capítulos nos lo muestran efectivamente desplazándose a través de un paisaje desprovisto de grandeza donde no fal. $\tan$ ferroviarios, colchas, lavatorios, bacinillas, carcajadas vulgares, relaciones adulterinas, chismografía pequeña. En ese paisaje cerrado, dentro de sus límites, tiende a surgir una posibilidad de vida que logra mantener al narrador. Fugazmente recobra jirones del pasado, reconoce a Irene en mujeres ocasionales $y$, a veces, por el sortilegio de relaciones amorosas, alcanza a pisar los límites del territorio perdido, desgraciadamente en forma imperfecta y pasajera, y la verdad es que la totalidad de su vida "va tomando un aire de bancarrota y de término".

Para él, todas las horas son iguales y se tiran a estrellones sobre el mismo atardecer. De pronto, cuando esta sensación se hace más aguda, con lucidez repentina exclama:

$a$ veces, cuando el aburrimiento es demasiado grande, este destierro me parece muy amargo.

Efectivamente, aun cuando los limites geográficos no hayan variado fundamentalmente, la relación entre el ámbito terrestre y su habitante ha sido alterado en lo profundo. Esta sensación negativa se agudiza en esta parte de su confesión y culmina cuando se dice:

Bueno, esto debe tener algún fin. O tal vez, éste es el fin.

$Y$ así lo hace. De inmediato retrocede y escoge el camino opuesto: el de la venganza. Dentro de la abarcadora psicología de este prota- 
gonista, escoger el camino inverso no es contradictorio. La huida que hasta aquí ha intentado sin éxito se convierte ahora, a la luz de su nueva determinación, en una forma de venganza. No ha estado huyendo sino reconociendo el terreno exterior ("todos los paraderos de Florencio, los nombres, las profesiones, las ciudades y los campos en que cruzó el paso de mi antiguo camarada") y el interior ("el ataque lo he meditado detalle por detalle, volviéndome loco de noche, revolcando esa acción desesperada que debe libertar mi espíritu"). Finalmente, la certeza de que se enfrentará a su amigo-enemigo, y de que alguno de los dos quedará allí muerto "por una inmediata voluntad humana" colo$\mathrm{ca}$ una nota esperanzada en su vida abúlica. Basta que adopte esa decisión en forma firme para que entonces nuevamente la noche comience a "palpitar encima de su lecho" y comience a recibir de nuevo la sen. sación del olor del mar. Sin embargo, es en el último capítulo donde tendremos a nuestro personaje en forma total. Con todos los titubeos y vacilaciones propios de un ser de contextura compleja. De un lado, su ardiente deseo de venganza, no tanto por un sentida justiciero ni de placer personal, sino como un acto liberador, $y$, en cierto sentido, como un acto capaz de volver a colocar su mundo en equilibrio, al restar con una acción pasional otra ejecutada en menoscabo de su serena disposición. Pero le vemos, al mismo tiempo que decidido, vacilante, atento a los pequeños matices ("mi antiguo compañero roncaba a tropezones"). Vienen a su mente, en ese momento crucial, escenas de la vida pasada en común (robos de animales perpetrados en conjunto) y luego, la invalidez de su sueño, y finalmente, la posibilidad de que él esté soñando con Irene y al tronchar su vida se tronche también, nuevamente, la de ella. Todo esto nos aleja paulatinamente de ese instante en que vimos brillando el arma asesina sobre el cuerpo indefenso de la víctima; nos aleja tanto que pensamos que es apenas un sueño, menos que eso. Sin embargo, si para nosotros el resultado pudo ser frustrante, pues no advertimos ninguna mutación concreta de la realidad, para su actor resulta suficiente y definitivo: catártico. En él, ese sólo intento, por fallido que sea, y lo haya sido en su existencia consciente o en la onírica, basta. Ha sido su acción humana suficiente para deshacer "ese tumulto" y para devolverle, con los ojos de una nueva aurora todavía impregnada de llanto, la nueva esperanza liberadora de su pequeña, intima y grandiosa aventura. Oigámosle:

Ahora estoy acodado junto a la ventana y una gran tristeza empaña los vidrios. ¿Qué es esto? ¿Dónde estuve? He aquí que de 
esta casa silenciosa brota también el olor del mar, como saliendo de una gran valva oceánica, y donde estoy inmóvil.

Es hora, porque la soledad comienza a poblarse de monstruos; la noche titila en una punta con colores caídos, desiertos, y el alba saca llorando los ojos del agua.

* * * *

El resto de los personajes, comparados con el protagonista, son de un esquematismo extremo. Irene, para ser caracterizada, exige apenas tres adjetivos ("gruesa, rubia, habladora"). En una línea cabe la descripción de su vida ("lava, canta, es ágil, rápida, garabatea los papeles con manos inverosímiles") y para sintetizarla, una sola imagen basta: es saludable "como piedra de arroyo".

Estos datos nos bastan para entender que no es ella capaz de despertar en el hablante un gran amor, pero sí, en cambio, por sus carac. terísticas vulgares, si se quiere, pero complementarias de las de él, una grata sensación de armonía amorosa. El la ama con tranquilidad hasta que su relación comienza a cargarse de premoniciones funestas. Su muerte violenta viene, por último, a otorgarle una dimensión ajena a ella misma. Primero, la poderosa subjetividad de su amante y luega el acto brutal de su marido son acaso sus únicos momentos relevantes, momentos en los que desempeña un papel completamente pasivo.

Florencio, su marido, es un hombre entregado a la acción. Si hay que robar, roba; si hay que matar, mata. Carece de una dimensión interior que le conceda ningún interés. Es otra fuerza de la naturaleza que reacciona tan elementalmente como ella. Apenas tiene subjetividad, casi no habla. Sin embargo, embellece su asesinato, si cabe la expresión, yendo en busca del tácito responsable de la muerte, utilizando su acostumbrada parquedad expresiva en ese magistral

-Es para un viaje largo, niño.

Magistral, porque en el vocablo largo se está refiriendo no al camino que debe recorrer hasta su casa, sino que va implícita la fuga y persecución posteriores; y porque en la voz niño manifiesta él toda su superioridad de hombre plantado en la realidad y capaz de actuar en forma contundente, como ha de quedar de manifiesto cuando lle. gue la hora de la acción: él pudo matar, no su rival.

Hay por ahí otra figura femenina que merece ser nombrada por el narrador más de una vez: es Lucía, que domina el capítulo décimopri- 
mero. Aunque las condiciones objetivas de la relación amorosa sean similares a las que el narrador mantenía con Irene, podemos leer entre las líneas de este capítulo la distancia fundamental que las separa. Irene era una mujer vulgar, pero auténtica y sana. Una piedra de arroyo. Lucía, en cambio, es acreedora de adjetivos de índole mucho más sofisticada, pero que, confrontados con el particular mundo de su aman. te resultan evidentemente desvalorizadores debido a su fuerte carga mundana, frívola y superficial. Acuerda plenamente esta mujer con el período vital del protagonista, a quien su obsesión de huida o venganza le ha alejado del contexto geográfico que le comunicaba su vigor. Ella es "atrayente, aficionada a consultar adivinas, tiene dibujos de la academia (adviértase el contraste con los 'monos inverosímiles' que ga. rabateaba Irene), su cabeza teñida, sus ojos de pájaro alocado, nunca pudo entender nada". Pero, como dice el narrador, "poco importa". Requerirá tal vez un esfuerzo superior instalarla a ella, legítimamente, en su mundo lírico-amoroso, pero ya veremos que, como siempre, su condición triunfa sobre la adversidad. El es capaz de levantarla no sólo cuando saltan pequeñas charcas ("con su alegría, tanto como pueden sus fuerzas") sino también en el momento en que su amor exige cierto nivel humano. Tanto como pueden sus fuerzas, él la ayuda a saltar y entonces ya han llegado a un punto de encuentro, a aquél en el que con el más suave de sus besos la hace "caer dulcemente hacia atras".

El resto de los personajes es pura utilería. Menos importante que, por ejemplo, las coigüillas del potrero desde donde roban caballos. A ningún ser humano le concede el narrador su mirada en profundidad. Todos ellos son meros pretextos para que, a veces, la acción avance, pero su función es fundamentalmente decorativa. $Y$ esto acontece también, en alguna medida, con los personajes mencionados, Irene, Florencio y Lucia. No valen por sí mismos, son intercambiables. Sería un error pensar que la aventura a que el narrador nos invita la provocan tales personas. Ha sido él solamente, y su peripecia ha sido básicamente interior. Por eso, no tiene mayor importancia que el acto final, el enfrentamiento entre vengador y vengado se realice dentro de los límites irreales del sueño.

No es fácil señalar qué ideas soportan el complejo temático. La obra no aspira, como ya he expresado, a una coherencia absoluta. La mayor pretensión que podríamos intuir sería la de lograr una unidad de tono. Nos lleva, y ese es a mi juicio el mérito fundamentanta a 
traspasar los límites de una realidad insignificante para asomarnos a un orden lírico en el que las pequeñas rugosidades del vivir cotidiano vienen a ser pliegues de una armonía más vasta y superior. Por eso es que la pasión, que aparece colándose de improviso entre este universo bien ensamblado, llega a desbaratarlo todo. Cierra, corta el vínculo que nutre de esperanza al habitante. Sólo mediante su dolorosa odisea y gracias al concurso generoso de la naturaleza, surge para él, con el amanecer de un nuevo día, otra esperanza, no sólo nueva sino de más valiosa entidad que la anterior. Aquélla era puramente animal, esta es, además, biográfica.

El protagonista ha estado más allá del límite y él conserva, confusamente, su recuerdo. También la Naturaleza ha presenciado el suceso y simultáneamente, con el inicio de un nuevo ciclo, hace brotar para él, "como saliendo de una gran valva oceánica", el amado olor del mar. Ya sabemos entonces que en esta empresa íntima está salvado. "Es hora", porque ya la soledad (de su destierro, de su incomunicación con los grandes elementos naturales) era demasiado prolongada y comenzaba a poblarse de monstruos (los fantasmas persistentes de la mujer asesinada y de su asesino durmiendo a tropezones $y$, sobre todo, esa ladrona - la muerte- siempre más grande que su apariencia encogida y desapercibida). El aliento del hombre empaña los vidrios, la noche titila frente a él, desde la ventana la observa con gran tristeza y advierte que, con un sentimiento semejante, fraterno,

el alba saca llorando los ojos del agua.

La antigua identidad entre el habitante y la Naturaleza ha sido, de este modo, restablecida.

Carlos Cortínez

University of lowa 
